\title{
Reflexiones sobre el futuro de América Latina
}

El tema que se ha sugerido tratar es el de América Latina y su destino. Es un tema recurrente en nuestras mentes y en nuestros debates, muchas veces cargado de angustia. ¿Qué somos? ¿Hacia dónde vamos? son preguntas permanentemente planteadas en Ibero América. El ensayo de sus respuestas es el inicio de una formulación de nuestro destino.

Para mí, lo que más da sentido a esta conversación universitaria, en la más antigua universidad de América, es mi convencimiento que debemos y podemos formular un destino para América Latina; que nuestro destino debe ser un acto creativo del hombre americano, un acto de voluntad, una tarea a realizar por nosotros o para ser más preciso por vosotros, por la juventud de la República Dominicana, por la juventud toda de la América Latina.

Formular nuestro destino es la obra de todos nosotros, pero alcanzarlo es la responsabilidad de vuestra generación. Porque así pienso, asigno importancia a este encuentro y creo que pueden tener algún valor mis reflexiones. No es mi intención hacer un análisis de la situación actual de nuestro continente desde el punto de vista de un economista, de un sociólogo o de un jurista. Desde estas visiones es frecuente proyectar imágenes pequeñas y agotadas. Mirarlas así nos impide ver en profundidad la naturaleza del ser americano, el verdadero horizonte del hombre y de la mujer de estas tierras. Analizar el hambre o el desempleo, la urbanización desordenada y la desorganización social, el precio del café o las exportaciones de banano, los tratados de paz y las amenazas de guerra, las inversiones en mineria y la producción de textiles, las dictaduras, la violación de derechos humanos, son tareas fundamentales que revelan un estado de las cosas, pero no un destino de los hombres.

Se trata de mirar superando los límites impuestos a la movilidad intelectual del hombre y a su creatividad. En nuestra búsqueda de destino, debemos agrandar el alcance de nuestras ideas, para pensar con amplitud geográfica y extendernos en el tiempo. Pero también debemos mirarnos a nosotros mismos, en nuestros hechos y en nuestra existencia, evitando mantenernos en la superficie de la historia de unos pocos años, o en las interpretaciones de los hechos inmediatos o de las circunstancias.

Trabajo basado en una conferencia pronunciada por el autor en la Universidad Autónoma de Santo Domingo, el 30 de octubre de 1978, y publicado con su expresa autorización. 
Debemos, asimismo, tener capacidad de percibir el desarrollo irresistible escondido en el lento suceder, comprender la extrema tensión escondida tras la apariencia de inmovilidad de nuestras sociedades. entender que en nuestro continente lo totalmente nuevo va naciendo ya en la monótona repetición de los hechos cotidianos.

Debemos mirar con sentido de conjunto comprendiendo que el destino de América no será diseñado por los que han sido propietarios del pasado, por los vicarios de empresas transnacionales, por el acuerdo o el desacuerdo de generales o por una institución internacional. Será el producto de un inmenso y misterioso esfuerzo intelectual, llevado a cabo por miles, millones de personas en un trabajo masivo de reinterpretación, exámen y testimonio realizado en libertad, donde esta se da, o en la oscuridad o en el exilio.

Sugiero en fin, tender una mirada liberada de la tiranía de ortodoxias y tabúes remanentes de visiones ajenas al continente, tolerante de la diversidad y hospitalaria de las ideas que delatan las tensiones reales y los conflictos existentes en la vida de nuestra América.

El hombre americano es el producto de un encuentro único en la historia humana por la diversidad de las culturas que concurrieron, por lo profundo y lo abrupto de ese encuentro. El europeo penetró en las civilizaciones indígenas $\mathrm{y}$ en este encuentro ambos cambiaron para crear un hecho nuevo, en el cual se inserta además poderosamente, el africano. Se originó así una cultura distinta que ha creado un sistema de significados, de normas, de opiniones, con las cuales diseñamos nuestras acciones e interpretamos las de otros. De él no nos podemos desprender como quien se cambia vestiduras cuando cambia la moda. Con él vivimos y en él se producen los irresistibles cambios que deben moldear nuestro destino. Porque ese sistema de normas, opiniones y formas de comportamiento, constituye sólo la punta del iceberg que es nuestra cultura y bajo esa punta, escondido por un mar de hechos pequeños de acontecimientos diarios, existe un sistema de valores profundamente enraízado, herencia de aquel encuentro que aún no agota su creación. entre el indígena, el europeo y el africano.

Se suele olvidar el hecho indígena pero vale la pena recordar la famosa carta que desde esta tierra escribiera Colón a los Reyes Católicos que tuvo una influencia decisiva en la conciencia europea con alcances que aún ruedan en la evolución de las ideas. Colón describe allí que ha llegado a una tierra - esta tierra dominicana, y la caribeña que la circunda- donde hay unos hombres que no son como los europeos, que viven pacíficamente, que no tienen armas, que no tienen propiedad privada, que se aman entre sí y que son felices. Es la primera vez que aparece la idea de la felicidad asociada a la sociedad humana, después de la precaria experiencia de Adán y Eva.

En ese sistema de valores y en ese proceso creativo que no se agota está nuestro destino, un destino dictado antes que nada por los iberoamericanos. 
Allí está también el origen de la tensión profunda que se agita a lo largo del continente, pero también cstá la tremenda potencialidad auténticamente creativa de América Latina, que no puede ser copia de la civilización anglosajona sino la versión de una nueva sociedad que exprese en una forma distinta los valores profundos de Occidente.

El éxito ha sido sólo parcial. En América Latina no se han dado resultados eepectaculares. Se han dado éxitos individuales y sociales pero también se presentan miserias y fracasos.

Las causas son variadas $y$, por lo mismo, sujetas a diversas interpretaciones, enfoques y opiniones. Ha habido algunas informadas. Otras han sido ignorantes.

Se ha dicho que el hombre latinoamericano es reacio a la disciplina, carente de imaginación, desprovisto de la voluntad que exige el avance hacia el futuro. Todo ello es falso. El atraso relativo de América Latina frente a Occidente tiene causas más profundas, tiene razones que no radican en el ser americano, que no están en su hombre. Las razones, las causas, están en motivos históricos que, generados en otros continentes, tuvieron consecuencias adversas en América Latina.

Están en una economía que nació distorsionada, como consecuencia del colonialismo y de la forma que el comercio internacional tomó durante siglos. Está en su geografía difícil, en muchos aspectos, hasta hoy día indomable. Está en que a América Latina llegaron juntas la revolución tecnológica y la revolución industrial. Está en que habiendo heredado del espíritu europeo, mundo y trascendencia, creencia $y$ fé, técnica moderna y religión, no hemos jerarquizado estos valores en su valor relativo del uno al otro ni los hemos adaptado o recreado en función de nuestros intereses culturales o materiales.

América Latina ha sido receptáculo de doctrinas y filosofías creadas en otro continente, campo para inversiones originadas en otras economías, productora de bienes para otros mercados, terreno para expresiones inspiradas en otras naciones.

Así se conjuró el atraso de América Latina y las penurias de su existencia y se impidió a este continente utilizar sus imaginaciones e inteligencias para crear su propia entidad.

Hemos vivido muchos años con una fé sin ciencia, con religión sin técnica moderna $y$ con trascendencia $\sin$ mundo. Tantas naciones han vivido en un marco estrecho, de mezquinas historias nacionales disolventes de un desarrollo auténtico, de dictaduras infames, de dependencias asfixiantes, de artificios desnaturalizador por imponer freno a nuestro desenvolvimiento humano. Por ello somos aún seres inacabados.

Por estar aún creándonos, nuestro juicio colectivo sobre el propósito y sentido del hombre en nuestra sociedad no tiene certeza, ni carácter definitivo. No tenemos confianza en definir nuestro lugar en el mundo porque no estamos seguros de nosotros mismos. Somos escépticos cuando no temerosos frente al elogio o a las críticas sinceras de los hechos hu- 
manos y sólo en lo profundo de nuestras conciencias admitimos el juicio como un ensayo de aclarar nuestra responsabilidades. Pero en el suceder de estos juicios personales, en la agitación por corregir la injusticia, en la organización por alcanzar la libertad, en la lucha por respetar la dignidad en movimientos abiertos o imperceptibles, hay una fuerza tremenda que emerge, auténtica, indetenible.

Estas características están en el germen del hombre americano, capaz de crear una sociedad que anime la espontaneidad, que sostenga la tolerancia y que genere la solidaridad.

Si damos real sentido a nuestra mirada, podemos formular nuestro destino.

Al intentar descubrir el destino que nos es posible y los elementos en que está su germen, deseo concentrarme en el hombre, interpretándolo como esencialmente libre, como un ser creativo y lo que es mas impor. tante, auto creativo. Un ser humano capaz de cambiarse a sí mismo y de cambiar el ambiente en que vive. Si me desean clasificar me adelanto a decir que mi pensamiento es voluntarista, orientado a la acción y alejado del determinismo.

Continuemos la exploración de nuestro destino analizando el pensamiento y los hechos como hoy día se mencionan.

Durante muchos años, se trabajó con la idea de crecimiento, que sólo ha indicado en la práctica una suma de bienes y servicios, medibles económicamente. Pronto se encontraron deficiencias muy profundas en la idea de que el crecimiento económico era suficiente para medir las dimensiones reales de la evolución del proceso humano, colectivo o individual. Y fue así como se avanzó del concepto de crecimiento al de desarrollo. Pero, aunque desde hace algunas décadas se habla de desarrollo, este concepto ha seguido explorado y verificado en términos de crecimiento económico, es cierto que con algunos aditamentos socia les, pero en definitiva, en estos campos del crecimiento y del desarrollo los que inspiran, deciden y después miden han sido los economistas, que han determinado que la carga de valorización de los factores eco. nómicos en el desarrollo debe ser sostenida y preponderante.

Recientemente se ha comenzado a hablar de desarrollo integral, concepto más comprensivo en el cual se hace presente el hombre como objeto y sujeto del desarrollo, como actor y destinatario de este proceso. Ya no solamente se tiene en cuenta qué elementos componen al desarrollo, cuáles son sus factores constitutivos, cuáles son sus posibilidades, cuál es su aceleración, cómo se maneja y dirije un fenómeno de desarrollo, sino algo que es aún más importante, que es saber hacia donde se va, qué se pretende, cuál es el destino de lo que se llama "desarrollo".

Todos entendemos que en un país que no ha cubierto sus necesidades fundamentales, donde los hombres, mujeres y niños no han resuelto sus necesidades mínimas, el desarrollo tiene una interpretación natural, obvia, contra la cual nadie podría levantar la voz. Satisfacer las ne. cesidades básicas es una tarea primordial. Pero hay en el mundo ur 
gran hipocresía. Todos hablan en términos de desarrollo, los regímenes más variados, incluso algunos que practican políticas que son conducentes precisamente a negar todo valor humano al desarrollo. Sin embargo, existe una conciencia cada vez más generalizada de que a pesar de los regimenes y de los sistemas, existen valores éticos que están antes y por encima de las manipulaciones económicas. De esta concepción del desarrollo o del estilo del desarrollo, arranca el compromiso ineludible que existe entre crecimiento, capitalización por y para toda la comunidad y participacón; la inaceptabilidad de la extrema pobreza; la exigencia de la justicia en la distribución del producto del esfuerzo social y del consiguiente rol del Estado; la participación de la comunidad en el esfuerzo colectivo, en las decisiones y en los beneficios. Pero, hay algo más profundo: el concepto del desarrollo, que tiene al hombre como sujeto y como objeto, sólo puede basarse en la democracia que en definitiva es la expresión política de la vida social entendida, tal como se define tradicionalmente, como gobierno de! pueblo, para el pueblo y por el pueblo.

El problema no es el objetivo, porque todos parecen estar de acuerdo; el problema es sobre el concepto y sobre el método. Cómo se obtiene el desarrollo, dónde está aquello que constituye su dinámica, dónde están sus lineamientos. $¿$ Se ha desarrollado efectivamente el ser moderno, se ha desarrollado el ser occidental? ¿Ser moderno significa haber asumido los beneficios de la ciencia y la téenica actual, tal como esa ciencia y esa técnica han sido la expresión creativa de otros pueblos, en otras culturas y en todo caso, en una acumulación de riqueza diez o más veces mayor que la nuestra? En este sentido América Latina entera, todos sus habitantes no llegarán a ser modernos antes de muchas décadas, cuando los modelos del modernismo sean otros. Podemos dejar de ser pobres —según el metro actual - pero corremos el riesgo de llegàr a ser anticuados o de haber alcanzado una civilización desaparecida. ¿Es nuestro destino repetir el desarrollo de los Estados Unidos sin haber vivido el siglo $\mathrm{xIx}$ y el $\mathrm{xx}$ que ellos han vivido? ¿Significa ser más parecidos a Europa, sin el pasado de Europa? ¿Hasta qué punto es efectivo que América Latina está mucho mejor hoy porque tiene un producto igual al de la Comunidad Europea en los años 50, y que estaremos mejor porque en el año 90 tendremos un producto igual al de Europa en los años 70 ? ¿Hemos avanzado realmente hacia algo nuevo, propio y distinto, o hemos progresado o algunos sectores han avanzado solamente en medidas cuantitativas, copiando mecánicamente lo que otros, en otras partes hicicron antes?

El desarrollo, y por ello el camino hacia nuestro destino, responde a dos estímulos fundamentales; por una parte a la natural vocación biológica, intelectual y espiritual del ser humano de progresar, de proyectarse, de crecer, de conquistar, de conocer, de liberarse del temor, de la miscria, de controlar la natulareza para liberar sus calidades intelectuales; y por otra parte, a la acción externa, a la intercomunicación cre- 
ciente entre los pueblos, que transcurre a través del dinamismo en la creación tecnológica de los medios de comunicación y de otros factores externos. El dinamismo interno incorporado al fenómeno del desarrollo es un elemento extremadamente difícil de medir, pero de una aceleración creciente. Es allí de donde provienen los problemas, los conflictos, las graves tensiones que se advierten dentro de las naciones y entre unas naciones y otras.

El otro problema que se presenta en este movimiento es que en nuestros países, en aquellos que están buscando formas aceleradas de desarrollo, el motor del dinamismo se encuentra fuera de ellos mismos. El dínamo que genera el desarrollo está fuera de estos paises, está en las corporaciones multinacionales o en los centros donde se toman las grandes decisiones y donde se concentra la ciencia, la tecnología, los recursos financieros y su servidor, que es el poder político y militar. Cada nación quiere "ser", necesita vivir de su imagen y tiene derecho a que esa imagen sea realidad, sea conocida tal cual es por el mundo exterior. Pero existe un sistema de información destinado a servir intereses concretos que prescinde de esa realidad, la deforma cuando interesa y crea, a nivel mundial, un sistema de valores y de verdades que contamina la conciencia universal en forma agobiadora. Sólo recién se inicia, entre nuestros pueblos, la información no manipulada y se abre, con ella, el camino de la cooperación que en su dimensión sur-sur puede enriquecer substancialmente la auto suficiencia en el desarrollo. Esta capacidad transnacional del dinamismo del desarrollo crea tensiones extremadamente dificiles, que obligan a los gobernantes a una permanente vigilia para mantener un mínimo de autonomía en la toma de decisiones, en la obtención y asignación de los recursos, en la escogencia de la tecnología y en el cuidado de la vocación de cada pueblo que exige ser antes que tener. Es por ello que la prédica de la interdependencia - que es una realidad objetiva- como la panacea que hará un mundo igual y por lo tanto feliz, dominado por la tecnología de las naciones y de las regiones y de los hombres que requieren, como oxígeno vital, una autonomía, capacidad creativa propia y respeto a sus derechos.

¿Cuáles son las bases de un cambio de estilo que produzca no solamente un distinto signo en cuanto a la orientación del desarrollo, sino la satisfacción de necesidades básicas, que es lo que da sentido a la calidad de la vida? No cabe duda que ellas tocan derechamente a la estructura política de la nación. Es automática y necesaria la vinculación de causalidad entre el estilo de desarrollo prevaleciente en la América Latina hoy día y la creciente ruptura del consenso social que ha entronizado, en tantas partes, regímenes que limitan de una manera u otra las libertades fundamentales, tratando de poner "orden" en la economía en esas sociedades. 
Me quiero referir concretamente al hecho de que la ruptura democrática que se ha estado produciendo en los últimos tiempos en la América Latina no es la tradicional que correspondía a la voluntad de un matón que en un momento dado asumía el mando por vanidad o ambición de poder. Esta otra ruptura es más profunda porque es el resultado de un vacío de consenso. Es obvio que si del esfuerzo nacional se van a beneficiar sólo unos pocos, nunca se ha sabido que estos pocos repartan después su poder político o financiero, si la mayoría no está organizada o silenciada o si el Estado no interviene disponiendo de los excedentes. La ruptura a la obediencia a la ley es corriente porque la ley es mejor para unos que para otros. Se da frecuentemente el caso de que el Estado no protege al débil contra el fuerte, sino paradójicamente, la protección la da al fuerte porque está organizado mientras los débiles, los más, no lo están y porque los débiles, en sus demandas, atentan contra el sistema. Y a veces, Dios demora en ayudar a los más contra los menos, que tienen estructuras nacionales e internacionales de protección!!

Es curioso comprobar cómo los procesos revolucionarios de nuestros países han sido motivados - yo diría en su mayoría - por el reclamo de la libertad garantizada en la letra de todas las constituciones y no cumplida; por la aplicación de principios generalmente aceptados en el mundo occidental, pero no practicados en esos paises. Muchas revoluciones, las más, no se intentan contra los regímenes jurídicos cuando estos permiten expresar adecuadamente a la comunidad. Son obra de la frustración de una participación impedida, se realizan contra la violación de derechos humanos que son los propios de la civilización humanista occidental. Pues bien, el sentir estos valores como elemento cultural básico hace que cada uno de los latinoamericanos sienta la dignidad de ser humano, tal y como ello se concibe dentro de esa civilización. Pero la ausencia de fundamentos económicos y sociales que sostengan esos valores es la raíz de las dificultades, tensiones y rupturas que tenemos a la vista. Las tensiones por lograr ser, más que por tener, rompe el consenso social y sólo algunos grupos que pueden rea!mente hacerse respetar por la fuerza, quedan incorporados al derecho y a la ley, mientras la gran mayoria mira a la distancia la posibilidad de alcanzar las ventajas de esta civilización. Si pretenden reclamar para sí la cuota que les pertenece, se encuentran con que las pequeñas minorías son las que poseen la fuerza para sostener lo que se da en llamar el orden. Por ello es que una política de derechos humanos en nuestro continente es tan necesaria y está tan vinculada al desarrollo.

Pero quien no sepa mirar podría creer que esa apariencia de orden es una expresión de estabilidad y no verá la tensión irresistible que se genera al oprimir a un hombre en evolución, al hombre americano. No verá que la pasividad a veces sólo esconde la espera antes del rapto de rebeldía. El americano no cesará de buscar a veces imperceptiblemente otras en violentas expresiones, formas de conveniencia que durante este siglo no ha siquiera definido, menos aún encontrado. Ese destino 
que buscamos y tendremos será sí un destino diferenciado. Quiero decir con ello que no es posible, como se piensa en algunos centros políticos, académicos o burocráticos, que todos los pueblos tengan un mismo tipo de desarrollo, deban seguir un mismo modelo, como si todos fueran iguales y no tuvieran diferencias. Pero esta diferenciación es una característica que se da en el mismo momento en que se acumulan los factores de unidad. Me explico: en el mismo período en que el poder se concentra en el mundo y dentro de las naciones en el Estado o en las grandes corporaciones, el ser humano, las pequeñas comunidades, buscan su individualidad, luchan por proteger su autonomía esencial. Es así como, por ejemplo, en el mismo momento en que Europa se une, se hacen presente los regionalismos europeos; en el mismo momento en que Gran Bretaña se incorpora al Mercado Común, el Gobierno de ese país se ve obligado por razones culturales a dar ciertos niveles de autonomía a regiones importantes del reino. Es la misma situación de Francia y, definitivamente, es el problema de la nueva democracia española. El caso se repite en muchos otros países donde el proceso de unidad va aparejado, al mismo tiempo, con la búsqueda de ciertos tipos de autonomía que haga posible el oxígeno necesario para que las comunidades que conforman la unidad nacional tengan vigencia. Esta diversificación en el proceso del desarrollo es un regreso a la independencia o a la autonomía del ser humano que desea vivir de acuerdo con sus tradiciones culturales, con la ecología, con el medio al cual pertenece, en una palabra, dentro de una dimensión humana. La Nación está perdiendo su valor de categoría absoluta, globalizante, porque el hombre, la mujer, el ser humano está emergiendo con sus derechos inalienables.

La única forma en que un pueblo puede llegar a desarrollarse no es copiando a otros en un proceso de uniformidad creciente, sino robusteciendo su propia unidad, su propia entidad cultural. Es reflexionando, investigando, creando, dando un rol superior a la ciencia, a la preparación humana en función de una permanente e integral visión critica de nuestras sociedades.

Estoy convencido que América Latina ya no habrá vivido para sí el siglo veinte. Quiero decir con ello, que pasaremos directamente de! siglo xix al siglo veintiuno. En último análisis, la mayor garantía que tengo para creer que así será es que para nosotros ello es vitalmente necesario. Entrar de plano al siglo xxi nos significará pasar por encima, saltar una forma de desarrollo que ha herido al hombre y a la naturaleza, que se centró más en las cosas que en las personas, que respetó más a quien adquiría que a quien creaba, que puso el memorandum por sobre la poesía, al curriculum-vitae por sobre la biografia, a la máquina por sobre quien la trabaja, y a la fuerza sobre la ley y el derecho.

Grupos cada vez más numerosos y organizados del occidente desarrollado comprenden la urgencia de cambiar el rumbo tomado durante este siglo y construir un futuro diferente. Esos grupos tienen creciente 
influencia. Sucesivamente van trizando los valores que sostuvieron el estilo de desarrollo de esta centuria.

En nuestra cultura, en esta cultura del encuentro indigena, hispano y africano, están enraizados valores, con muchos siglos de permanencia que aman lo pequeño, que viven de lo humano y de lo divino, que aman sin mirar el color de la piel, que necesitan poesía en las cosas y en los hechos, que conocen la magia de la vida, que sienten una relación simbiótica con la naturaleza, para los cuales la ecología es más que una ciencia, es una experiencia vital, diaria. Así es como estoy convencido que nuestro destino no es $y$ nuestro pasado no ha sido crear nuevas formas de producir más bienes, sino dar un sentido humano a esa producción donde los bienes satisfagan más las necesidades que los deseos.

El hombre americano debe construir un destino en el cual en la diversidad dominen las tendencias a la unidad, en el cual continuemos construyéndonos y formando, como conjunto, nuestra identidad.

No se trata de rechazar las influencias externas, por el contrario.se trata de aceptarlas cuando ellas complementen nuestro ser, fortalecen nuestros valores, aseguran mejorar nuestra perspectiva. Se trata de aceptar lo extranjero cuando no signifique interferencia sino expresión legítima del contacto entre cultura en marcha.

Nuestro destino no es un destino de segunda clase, que nos haría entrar al futuro por la puerta de servicio. Se ha dado en decir ahora que seremos la clase media del mundo. ¡Glorioso destino histórico! Quienes así piensan creen que las estructuras sociales internas y las relaciones de poder internacional son estáticas, no siguen la dinámica de la lucha por la justicia, por la libertad, por la dignidad y por la conquista del poder de quienes han estado oprimidos, nacional o internacionalmente, rompiendo las amarras coloniales o buscando autonomía frente a las dependencias.

Los países árabes no eran considerados ni siquiera media clase hace diez años atrás. Por un acto político de voluntad colectiva, tomaron decisiones respecto a sus riquezas naturales que conmovieron al mundo y crearon una nueva dinámica histórica. Ya su estatus no es de clase media. Están entre los que deciden.

Al futuro se entra por muchas puertas, y no sólo por las que abrieron los anglosajones en la revolución industrial del siglo xix. América Latina entrará por la suya, porque este continente es una necesidad para la humanidad, porque es el continente más rico en recursos naturales, porque es el único que ha demostrado capacidad de integrar hombres venidos de todos los horizontes y a todos tratarlos como iguales, porque seremos 600 millones de hombres y mujeres en 25 años más, porque nuestra agricultura puede ayudar a alimentar al resto del mundo:

Anteayer el Rector de la Universidad Autónoma de Santo Domingo, Dr. Antonio Rosario, en su magnífica exposición nos hablaba de la fundamental importancia de querer, porque los que pueden no hacen las cosas, ni la historia; son los que quieren, los que la hacen. 
América Latina está pasando, creo, la peor etapa de su convulsionado proceso de liberación, de su voluntad de ser por sí misma. Aquí, en la República Dominicana, se ha dado un ejemplo admirable y el pueblo construye su destino en libertad. En otras partes, aún se sufre y se muere. Por eso nos duele Nicaragua. Pero, más allá de la oscuridad, hay un amanecer seguro.

No habrá desarrollo mientras no haya participación, ni ésta se dará sin libertad. Son estos los prerrequisitos de la posibilidad de una unidad en la acción que logre, a través de un acto de poder, una presencia activa y respetable de América Latina en el nuevo orden internacional.

Pero es importante observar cómo ese poder se está ya construyendo por la vitalidad creadora del hecho hispano-americano. España, ausente del interés de nuestra América por cuatro siglos expresa su voluntad de reintegrarse, de formar parte de la familia precisamente en el momento en que su sociedad se abre a una ancha vida democrática, diría más, porque España inicia su apertura democrática necesita volver a la vida internacional y ella comienza por reencontrarse con esta América. ¿No es esta coyuntura adecuada para concebir la formación de una comunidad con España de grandes potencialidades con alcances ibéricos? La comunidad de habla portuguesa es una realidad cuyo centro está en Brasil, pero Brasil es país de nuestra cultura, de nuestro mundo geográfico, que vive nuestros mismos valores y que, con su gran vitalidad desarrolla sus vínculos con Portugal y las nuevas naciones africanas de habla portuguesa. Por otra vertiente, Cuba, en audaces gestos de solidaridad ofrece también ejemplos de cooperación en esos nuevos países y es el Caribe de habla inglesa, al cual debemos incorporar plenamente a nuestro quehacer hispano-americano, como responsabili. dad de todos nuestros pueblos.

Pero hay otras dimensiones cuya importancia pasan todavía inadvertidas. Siempre hemos hablado de cómo defendernos de Estados Unidos, cómo distinguirnos o cómo entendernos con ese gran país del Norte. En el devenir histórico hay un nuevo elemento que tendrá profundas influencias en las relaciones entre América Latina y Estados Unidos. Preocupados de la influencia de ese país en nuestras sociedades, no nos damos cuenta que el mundo hispano latinoamericano ha entrado en los Estados Unidos e iniciado allí un proceso de influencia que puede tener insospechadas repercusiones. Ya hay en los Estados Unidos 16 millones de ciudadanos de orígen hispánico. A esa cifra deben agregarse más de siete millones de indocumentados. Hoy, Estados Unidos es el cuarto país hispánico del mundo y de seguirse la inmigración y el crecimiento vegetativo actuales, en diez años más ese país será el segundo país hispánico, mayor que España misma. Será la minoría más grande de Estados Unidos con consecuencia culturales y políticas de trascendencia. El hispanoamericano llega con un bagaje culturai con un idioma, con una religión, con un sistema de valores éticos, fa- 
miliares, artísticos que ya comienzan a expresarse con fuerza en el país del norte.

La comunidad ibero-americana está creciendo en número y en influencia. Llegará el día en que los pueblos crearan las estruturas políticas que le den unidad y dirección.

¿Es esto mirar muy lejos? $\mathrm{No}$, es el destino de una cultura que recién puede estar sacudiéndose de un letargo pero que está demostrando una gran fuerza creadora cuyos profetas, los poetas como Pedro Mir, Pablo Neruda y otros grandes, lo han escrito ya en el firmamento no superado de nuestra poesía. Son ellos los que dicen las verdades y anticipan los tiempos y los espacios, como cuando en el portentoso Viaje a la Muchedumbre de Pedro Mir, ese dice:

"Si alguien quiere saber cuál es mi patria se lo diré algún día

Cuando todo milagro sea posible y ya no sea milagro el de la vida:

Dirán que somos libres y golosos, que gozamos del pan y de la espiga, Que cada hombre tiene dignidad, cada mujer sonrisa.

Que tenemos la patria verdadera

y ésta también será la patria mía.

Si alguien quiere saber cual es mi patria se lo diré ese día."

Nuestro destino sólo puede construirse con las grandes mayorías convertidas en actores y ejecutores, con los pueblos hoy discriminados y atrasados.

No existe posibilidad de conservar nuestra cultura si el futuro es construido por élites desconectadas del pueblo, no alimentadas, no renovadas por el pueblo. La energía del hombre americano está en sus obreros, campesinos, estudiantes, empleados, empresarios, académicos y profesionales, en todos ellos, no en un grupo particular. Es esa energía la capaz de construir un destino en la medida en que su expresión se organice y respete y su unidad se preserve. En las élites actuales la dependencia ya ha hecho estrago y en muchos de sus miembros la mirada se encuentra fija en el exterior. El desarrollo del Norte podrá ser admirado por el pueblo, pero no lo ha deslumbrado, no ha quebrado su fibra ni ha roto su conexión vital con sus orígenes. Es en el pueblo donde está la 
capacidad creadora, es su origen el que conserva el tesoro de su futuro, de nuestro destino. Como lo dice la antigua copla popular dominicana:

\author{
"La madre que te parió \\ puede decir con verdá \\ que tiene rosa en su casa \\ sin que la tenga sembrá."
}

Sólo la calidad social de la construcción le da a ella permanencia sentido de futuro, optimismo. Ese proceso de construcción participada será un hecho generado por la socialización.

Por ello creo que la socialización, el empuje colectivo, el incremento de las interrelaciones entre las personas, el aumento de las acciones comunes, de las empresas llevadas a cabo por voluntad y consentimiento de todo el grupo social, son causa y efecto de la construcción futura, constituyen el camino hacia nuestro destino y nuestro destino mismo.

Pero ¿Cómo se crea ese destino? ¿Qué hace posible esa real socialización que está en la base del pensamiento cristiano y por ello tan hispano-americano? No hay otra forma que la democracia.

La democracia es la participación plena de la comunidad en la vida, en la toma de decisiones a distintos niveles; es la acción de la comunidad dinámica, organizada por razones de eficiencia bajo una autoridad; es esta democracia la que puede conducir este esfuerzo colectivo. Y el consenso se va a conseguir en la medida en que se satisfagan necesidades básicas, para lo cual se requiere como primera condición dotar a la comunidad de condiciones de libertad, del ejercicio del derecho político, del respeto mutuo en la solidaridad democrática, de la libertad entre iguales. Entre iguales, entre latinoamericanos, hoy día sometidos a tantas diferentes circunstancias, se puede crear, por estas condiciones de pertenencia a un mismo esquema de valores, una solidaridad que sea fuente de energías para construir, en esa zona del mundo, algo que podría ser un ejemplo, una casa digna, limpia, serena y pacifica para el hombre. 